\title{
Compressive Behaviour of Aluminium Pyramidal Lattice Material-Filled Tubes
}

\author{
Yingjie Huang ${ }^{1,2}$, Wenke Zha ${ }^{1}$, Yingying Xue ${ }^{3, *}$ and Zimu Shi ${ }^{2, *}$ \\ 1 School of Physics \& Electrical Engineering, Anyang Normal University, Anyang 455000, China; \\ yingjieh@mail.ustc.edu.cn (Y.H.); wkzha@vip.163.com (W.Z.) \\ 2 Key Laboratory of Materials Physics, Institute of Solid State Physics, Chinese Academy of Sciences, \\ Hefei 230031, China \\ 3 School of Electromechanical and Automotive Engineering, Yantai University, Yantai 264005, China \\ * Correspondence: xyy_0806@126.com (Y.X.); shizimu@issp.ac.cn (Z.S.)
}

Citation: Huang, Y.; Zha, W.; Xue, Y.; Shi, Z. Compressive Behaviour of Aluminium Pyramidal Lattice Material-Filled Tubes. Materials 2021, 14, 3817. https://doi.org/10.3390/ ma14143817

Academic Editor: Victor Songmene

Received: 2 June 2021

Accepted: 29 June 2021

Published: 8 July 2021

Publisher's Note: MDPI stays neutral with regard to jurisdictional claims in published maps and institutional affiliations.

Copyright: (c) 2021 by the authors. Licensee MDPI, Basel, Switzerland. This article is an open access article distributed under the terms and conditions of the Creative Commons Attribution (CC BY) license (https:// creativecommons.org/licenses/by/ $4.0 /)$.

\begin{abstract}
This study focuses on the uniaxial compressive behaviour of thin-walled Al alloy tubes filled with pyramidal lattice material. The mechanical properties of an empty tube, Al pyramidal lattice material, and pyramidal lattice material-filled tube were investigated. The results show that the pyramidal lattice material-filled tubes are stronger and provide greater energy absorption on account of the interaction between the pyramidal lattice material and the surrounding tube.
\end{abstract}

Keywords: multilayer structure; porous materials; aluminium pyramidal lattice material-filled tubes; mechanical properties; energy absorption

\section{Introduction}

Thin-walled tube structures act to buffer energy and as energy-absorbing components, have a wide range of potential applications in transportation and aerospace engineering [1-3] A thin-walled tube filled with a cellular structure is used to improve the bearing capacity and energy absorption characteristics of the structure. Its lightweight characteristics play an important role in reducing energy consumption and reducing air pollution [4-6]. Aluminum foam has the characteristics of low density, high porosity, high specific strength, and high specific stiffness, which is an ideal energy absorbing material $[7,8]$. In recent years, researchers have attempted to improve the mechanical and energy absorption properties of thin-walled metal tubes and aluminum foam by filling the metal tube with aluminium foam [6]. The results show that the combined structure has a more stable energy absorption process and higher energy absorption efficiency [9-13]. Taherishargh assessed the effect of temperature on the mechanical behaviour of aluminium-alloy foam-filled empty tubes and found that aluminium-alloy foam-filled tubes exhibited improved mechanical properties compared to empty steel tubes at each temperature tested [12]. Niknejad and Rahmani conducted theoretical analysis and an experimental study on hexagonal tubes filled with polyurethane foam and proposed a new theoretical model for the analysis thereof [14]. Duarte et al. studied the material properties of closed cell aluminium foam embedded in a single metal tube [9]. Cao investigated the performance of aluminium foam when used in an aluminium alloy thin-walled structure through uniaxial quasi-static compression tests and numerical simulation [15]. In short, some research results on aluminum foam-filled thin-walled structures have been obtained.

Mechanical properties are important indices guiding the choice of the application of structural materials. Lattice metallic materials are a type of new cellular material emerging in recent years, which have excellent specific stiffness and specific strength and have been applied in transportation structures for lightweight and protective structures due to their excellent energy absorbing ability [15-17]. The excellent features make them good filling materials in tandem with structural-grade tubes. However, according to the 
literature, the most common internal filler material is aluminium foam, and research into the mechanical properties of aluminium lattice material-filled tubes is sparse, despite their potentially excellent performance. The purpose of the present research was to fabricate and investigate the mechanical properties of aluminium pyramidal lattice material-filled tubes. The results show that the aluminium pyramidal lattice material-filled tubes were stronger and provided greater energy absorption than the empty tube and lattice material due to the interaction between the lattice material and the empty tube.

\section{Experimental Work}

\subsection{Structural Design}

The unit cell of the 3-D pyramidal lattice material including eight structural subunits is shown in Figure 1a: it is characterised by its top-to-top pyramidal structure. The periodic 3-D pyramidal lattice material can be obtained by extension through CATIA V5 R20 software, as shown in Figure 1b. To describe the structural features, three structural parameters are used: strut length $L$, diameter $D$, and inclination angle $\omega$ between the strut and the horizontal plane (Figure 1a). For pyramidal lattice material, the effect of the strut length or inclination angle is realised by changing the relative density of the lattice samples [18]. While the inclination angle is constant, the mechanical properties are related to the aspect ratio $L / D$ [19]. To keep the sample size constant, the included inclination angle $\omega$ and strut length $L$ were kept unchanged in the present research, and the relative density was changed by changing the diameter $D$. Several samples were designed (Table 1). The relative density of the pyramidal lattice materials is given by

$$
\bar{\rho}=\rho_{\mathrm{s}} / \rho_{0}
$$

where $\rho_{\mathrm{s}}$ and $\rho_{0}$ are the apparent density and the density of aluminium respectively, where $\rho_{\mathrm{s}}$ is determined by the mass and volume of the pyramidal lattice materials.

(a)

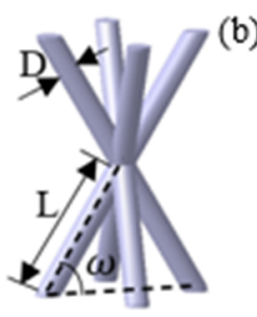

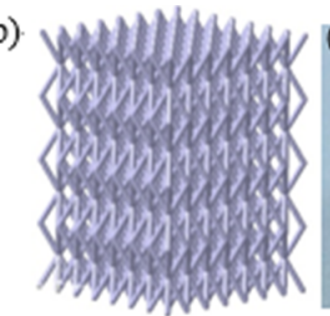

Figure 1. (a) The unit cell of the 3-D pyramid lattice material, (b) periodic 3-D pyramid lattice material, (c) aluminium pyramid lattice material.

Table 1. Structural parameters of the pyramidal unit cell.

\begin{tabular}{ccccc}
\hline Sample Number & $\boldsymbol{D}(\mathbf{m m})$ & $\boldsymbol{\omega}\left(^{\circ}\right)$ & $\boldsymbol{L}(\mathbf{m m})$ & $\overline{\boldsymbol{\rho}}$ \\
\hline $\mathbf{1}$ & 0.8 & 60 & 3 & 0.28 \\
$\mathbf{2}$ & 0.9 & 60 & 3 & 0.33 \\
$\mathbf{3}$ & 1.0 & 60 & 3 & 0.41 \\
\hline
\end{tabular}

\subsection{Fabrication of Lattice Samples}

The pyramidal lattice materials used in the present research were made of commercialgrade aluminium, and the fabrication method was similar to that used when producing other lattice structures [20]. First, the pyramidal lattice materials were designed through CATIA software, and the corresponding photosensitive resin patterns were prepared using a 3-D printer. The patterns were put in a container and then plaster was poured onto them. The patterns were removed, and solid plaster moulds were formed with a pyramidal lattice material cavity after drying and baking. Molten aluminium was then poured into the mould, and compressed air was fed to the mould to ensure that the molten aluminium filled 
all the fine cavities within the mould. Finally, the plaster shell mould was spray-washed, allowing collapse, and the plaster shell removed, leaving an aluminium lattice structure as shown in Figure 1c. The 6063 aluminium alloy empty tube specimens with length, width and height of 20, $20 \mathrm{~mm}$, and $27 \mathrm{~mm}$ respectively, and the wall thickness of $1 \mathrm{~mm}$ were filled with pyramidal lattice material. The pyramidal lattice material was squeezed into the 6063 aluminium alloy empty tube by a press-fit technique, and the resulting pyramidal lattice material-filled tubes are shown in Figure 2. The principle of thermal expansion and cold contraction was used to obtain an interference fit between pyramidal lattice material and 6063 aluminium alloy tube.

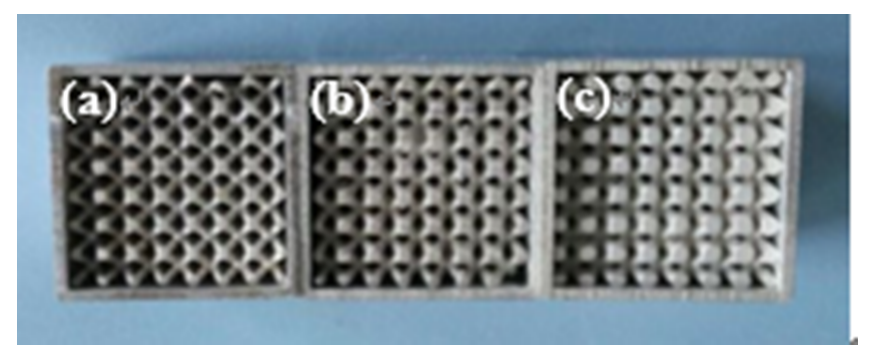

Figure 2. Pyramid lattice material-filled tube with different relative densities of lattice material: (a) 0.28 ; (b) 0.33 ; (c) 0.41 .

\subsection{Mechanical Measurement}

Mechanical measurements were conducted in a material measuring system (Instron 3369) at a rate of $2 \mathrm{~mm} / \mathrm{min}$. To avoid the influence of size effects on the mechanical properties of lattice materials, the number of unit cells in a sample was $7 / 7 / 4$ in the $X / Y / Z$-directions, respectively. The experiments were conducted on square samples based on three different geometrical configurations including pyramidal lattice materials, empty tubes, and pyramidal lattice material-filled tubes. Each compression test was conducted along the $Z$-axis of the pyramidal lattice materials. Three samples were tested for each structure, and the arithmetic mean of the measured data was taken as the final value representing each group of samples.

\section{Results and Discussion}

\subsection{Effects of Structural Parameters on Compression Mechanical Behaviour}

As shown in Table 1, when the strut length $L$ and inclination angle $\omega$ are constant, the relative density decreases with the increase of the diameter $D$. Figure 3 shows that for typical quasi-static stress-strain curves of Al pyramidal lattice materials, similar to other common porous or cellular metallic materials, the stress-strain behaviour of $\mathrm{Al}$ pyramidal lattice material exhibits a three-region characteristic including linear elastic, plateau, and densification regions [21,22]. Unlike the tensile-dominant lattice material, there is no softening beyond the linear elastic region of the stress-strain curve. Although the linear portion of the stress-strain characteristic for such lattice materials is not as large as that of stretch-led lattice materials, it has a stronger linear relationship than that of an open-cell aluminium foam. This may be due to the irregular arrangement of open-cell aluminium foams causing local buckling of some cells at lower stresses. It can be seen from Figure 4 that the whole compression deformation process of an empty tube can be divided into five regions: (A) elastic region, (B), the second region where the highest stress-drop occurs, (C) the third region of stress oscillation, and (D) the region in which the densification of the empty tube occurs. This is caused by buckling of the thin-walled 6063 aluminium alloy empty tube during axial compression. It is worth noting that the stress-strain behaviours of the pyramidal lattice material-filled tubes exhibit dissimilar features to the empty tube and are significantly different from the $\mathrm{Al}$ pyramidal lattice materials as shown in Figure 5. The stress-strain behaviour of the $\mathrm{Al}$ pyramidal lattice material exhibits a four-region characteristic: a linear elastic region, softening region, a plateau, and a densification region. 
6063 aluminium alloy tubes play a leading role in the linear elastic zone, so the stress decreases when the empty tube is rendered unstable. With increasing strain, due to the supporting action of the internal lattice material, the empty tube can no longer buckle, so the stress platform does not appear as a peak within the plateau region. In the elastic region, the stress-strain curves of pyramidal lattice material-filled tubes with three different relative densities are almost coincident. Moreover, the stress-strain curves of pyramidal lattice material-filled tubes with relative densities of 0.33 and 0.28 are similar; however, the plateau region of pyramidal lattice material-filled tubes with a relative density of 0.41 bears a greater stress and is much more stable (especially when the strain is less than 20\%), which can be attributed to the interaction between the empty tube and the struts of the Al pyramidal lattice materials. When the relative density of the lattice material is low, the lattice material is not dense enough to prevent deformation of the empty tube.

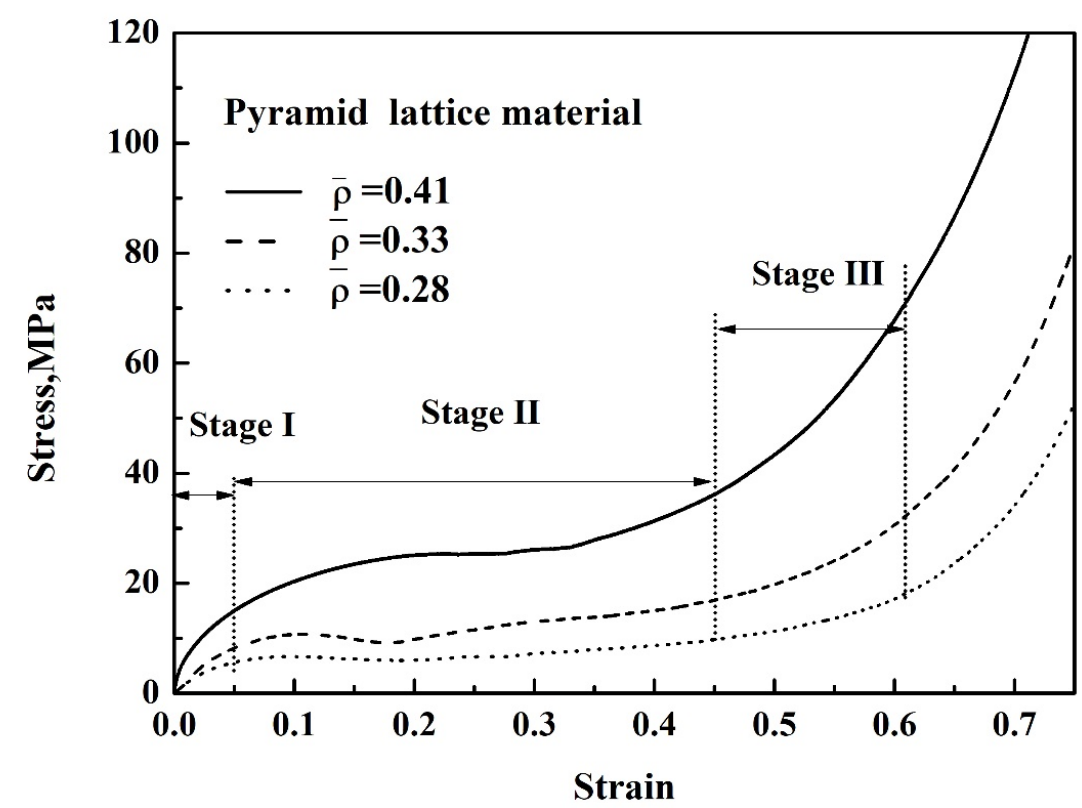

Figure 3. Stress-strain curves of the pyramid lattice material with different relative densities.

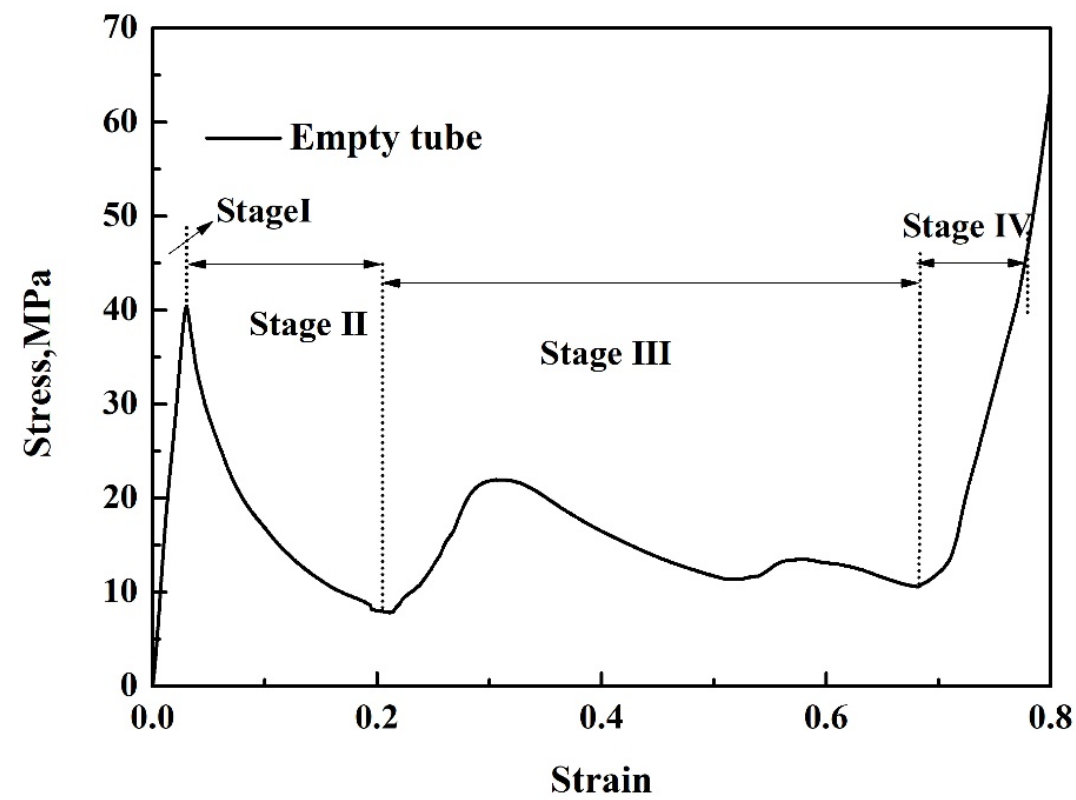

Figure 4. Stress-strain curves of the 6063 aluminium alloy empty tube. 


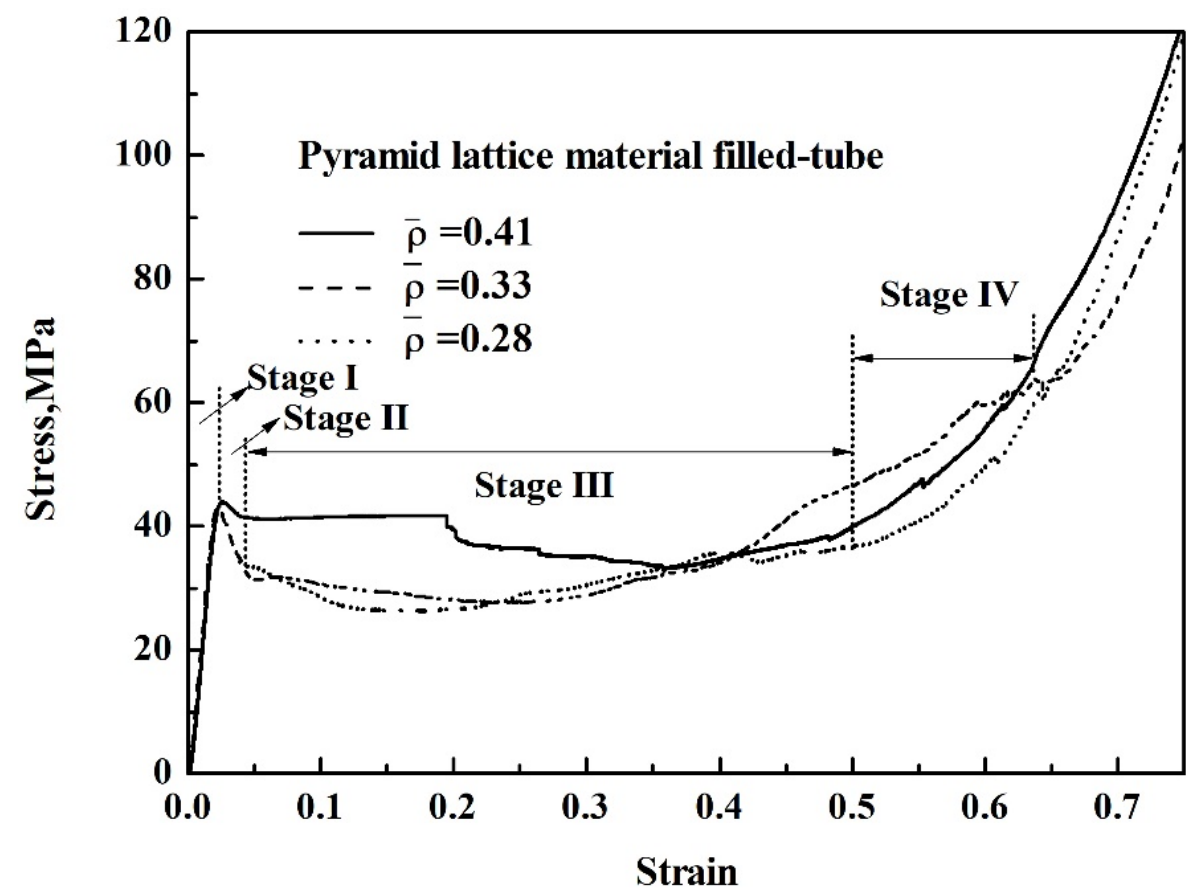

Figure 5. Stress-strain curves of the pyramid lattice material-filled tube with different relative densities.

Due to the lack of a pronounced yield stress in the pyramid lattice materials, the peak compressive strength was determined at an offset strain of 5\% [21], and the peak compressive strengths of pyramid lattice material filled-tubes and the empty tube were taken as the initial peak stress. It can be seen from Figure 6 that the peak compressive strength of the lattice material and that when it is filling a tube increases with its relative density; however, the increase in the peak compressive strength of the lattice material-filled tube is small, which is attributed to the fact that both the lattice material and the lattice material-filled tube are in the elastic zone before the peak compressive strength is reached, and the support effect on the lattice material is small.

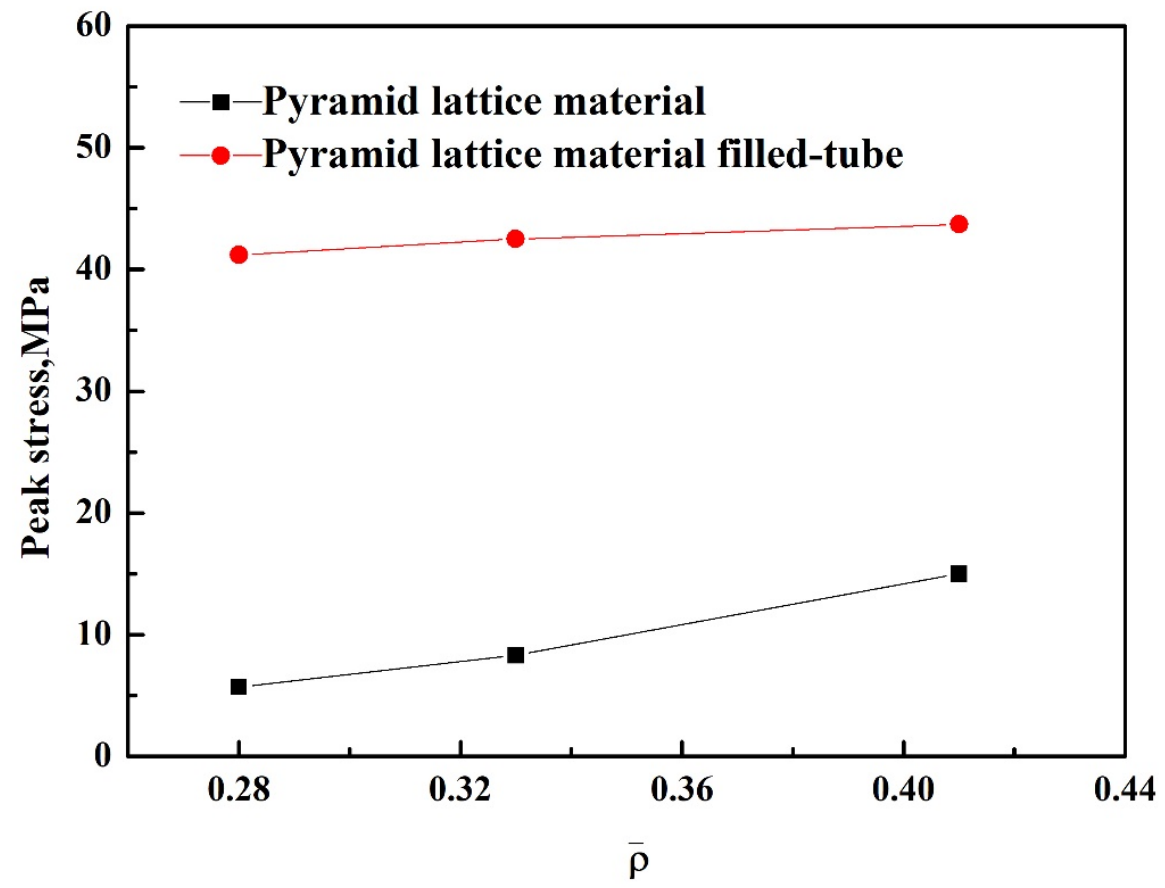

Figure 6. Peak stress of the pyramid lattice material and pyramid lattice material-filled tube with different relative densities. 
Figure 7 shows the engineering stress-strain curves of the pyramidal lattice materialfilled tube and the sum of the stresses on the pyramidal lattice material and empty tube. Figures 8-10 show that a pyramidal lattice material-filled tube is stiffer than the counterpart empty tube. In the elastic region, the stress-strain curve of the pyramidal lattice materialfilled tubes almost coincides with that of the empty tubes. This is because there is no bending deformation in the pyramidal lattice material, and it is the empty tube that mainly bears the load due to its much higher strength; thus, the response of the pyramidal lattice material-filled tubes reflects the empty tube's behaviour, giving two overlapped stressstrain curves. With increasing strain, the empty tube will buckle and appear concave or convex. The pyramidal lattice material in the interior cannot completely prevent this, therefore, the stress-strain curve trends downwards, but it also plays a certain role, so that the stress-strain curve will plateau. In the plateau region, the stress of pyramidal lattice material-filled tubes is higher than that of the empty tube and Al lattice material, and the stress on the composite material is much greater than the sum of the stresses on the $6063 \mathrm{Al}$ alloy tube and pure Al lattice material (Figure 7). This is due to the constraining effect of the empty tube on the deformation struts and the friction between the pyramidal lattice material and the empty tube; thus the stress and stability of the empty tube are improved. At the same time, it can be seen from the deformation pattern of the pyramidal lattice material that there is an obvious lateral expansion during the compression process (Figure 11), and the incorporation of pyramidal lattice materials within the empty tube significantly enhance its mechanical properties under compression. When the relative density of the pyramidal lattice material is 0.41 , it can be seen from Figure $7 \mathrm{c}$ that the sum of the stresses on the pyramidal lattice material and empty tube is higher than that on the pyramidal lattice material-filled tube over the range of strains from 0.3 to 0.5 . This is because the pyramidal lattice material with a relative density of 0.41 is much stronger than the empty tube and the interaction becomes stronger. The lateral expansion of the lattice material caused the rupture of the empty tube (Figure 10c).

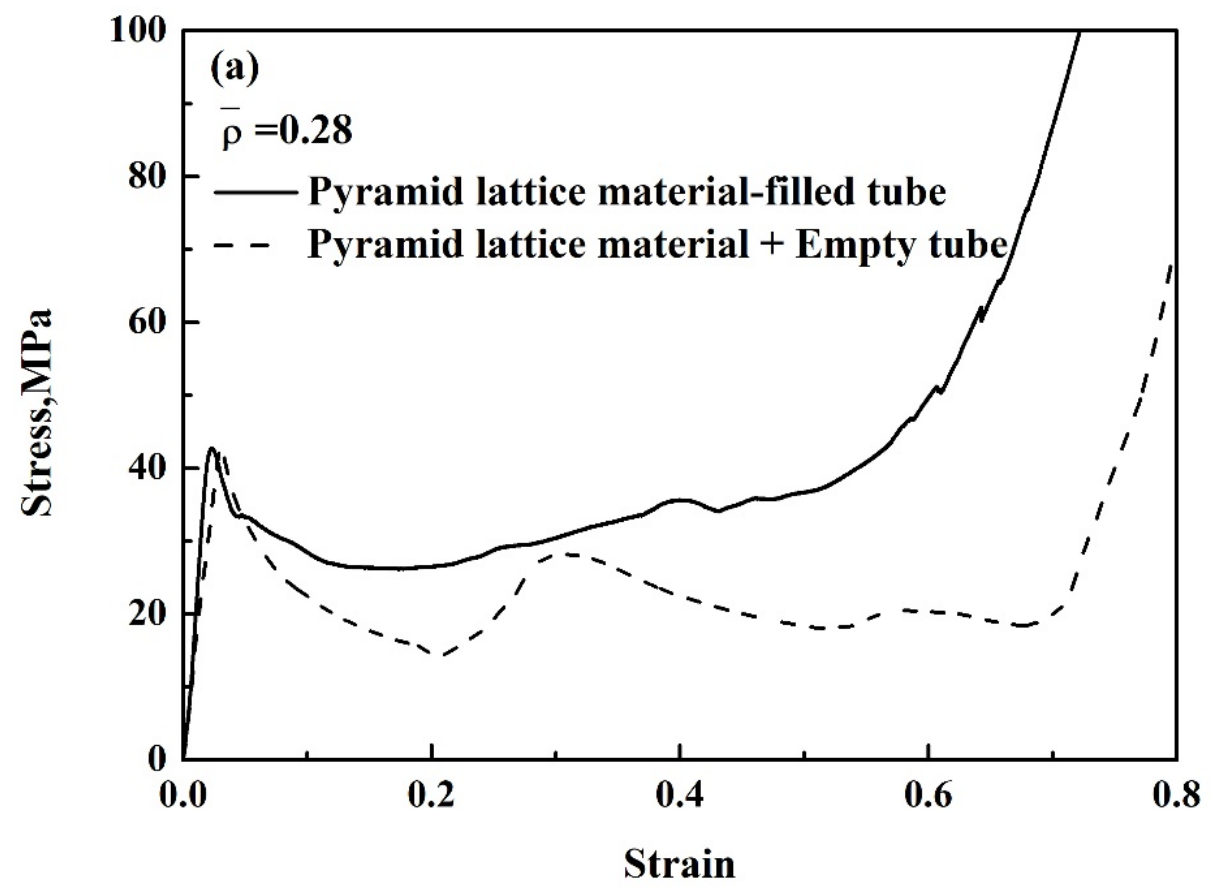

Figure 7. Cont. 

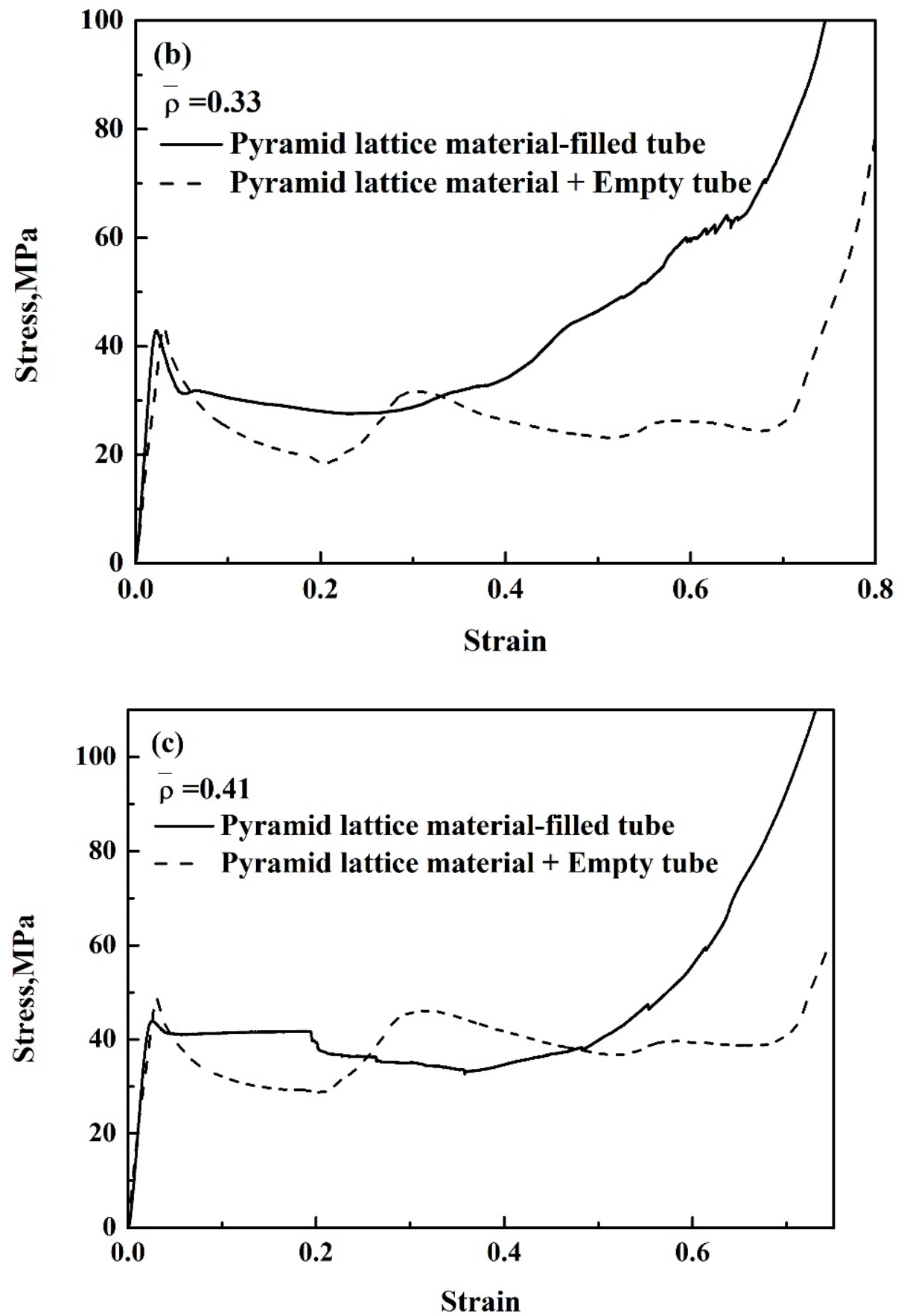

Figure 7. Stress-strain curves of the pyramid lattice material-filled tube and the pyramid lattice material + empty tube with lattice material of different relative densities: (a) 0.28 , (b) 0.33 , (c) 0.41 .
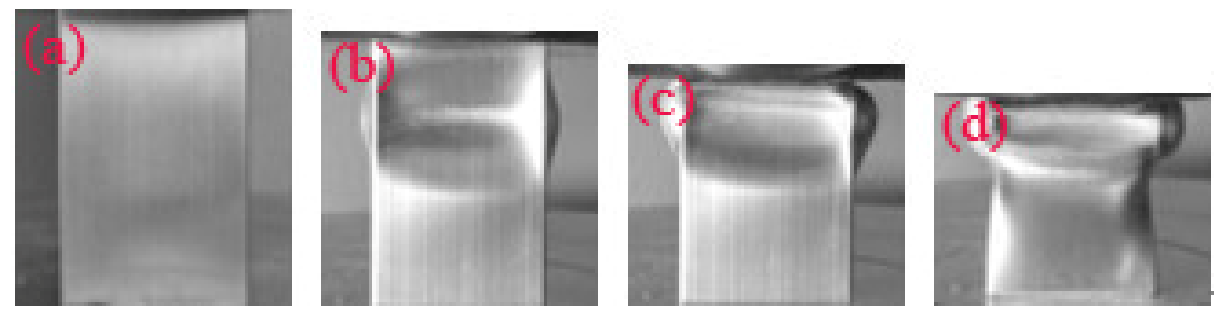

Figure 8. Typical deformation of an empty tube at a strain of (a) $2.6 \%$; (b) $10 \%$; (c) $20 \%$; (d) $30 \%$. 

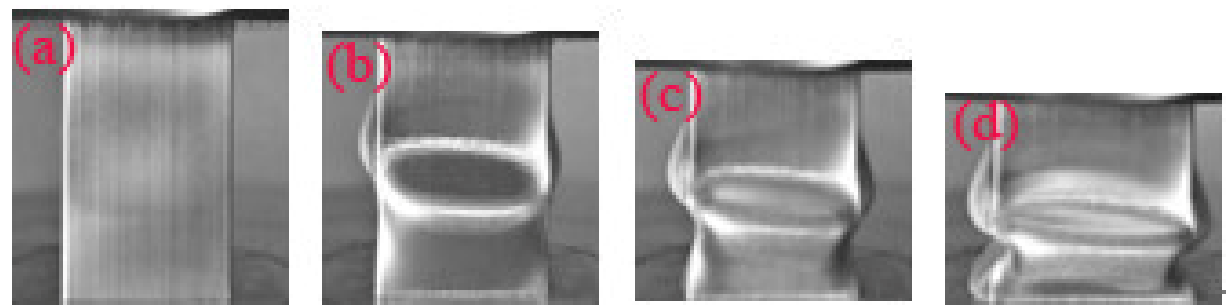

Figure 9. Typical deformation of the pyramid lattice material-filled tube with a relative density of the lattice material of 0.33 at a strain of (a) $2.6 \%$; (b) $10 \%$; (c) $20 \%$; (d) $30 \%$.
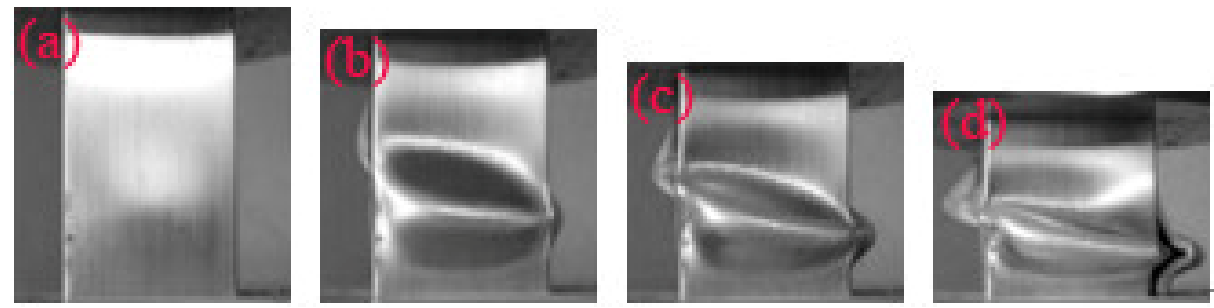

Figure 10. Typical deformation of the pyramid lattice material-filled tube with a relative density of the lattice material of 0.41 at a strain of (a) $2.6 \%$; (b) $10 \%$; (c) $20 \%$; (d) $30 \%$.
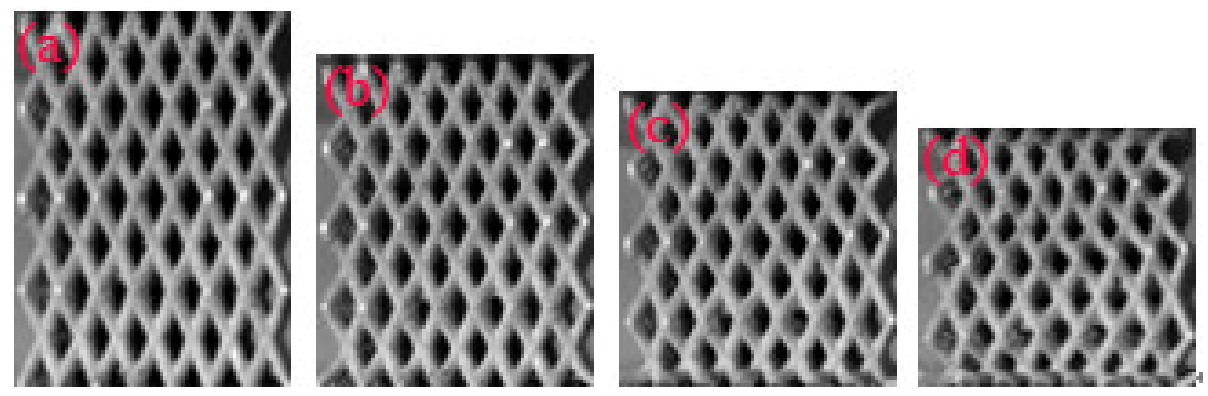

Figure 11. Typical deformation of the pyramid lattice material with a relative density of 0.41 at a strain of (a) 2.6\%; (b) 10\%; (c) 20\%; (d) 30\%.

\subsection{Effects of Structural Parameters on the Average Crushing Force}

The average crushing force is given by:

$$
F_{m}=1 / s \int_{0}^{s} F(s) d s
$$

where $s$ is the compression displacement, $F(s)$ denotes the force at displacement $s$.

The average crushing force-displacement curves of pyramidal lattice material-filled tube and empty tube are shown in Figure 12. The average crushing force-displacement curves of the pyramidal lattice material-filled tube and empty tube are similar. In the initial stage, the average crushing force increased rapidly with the increase of displacement and soon reached the peak value. After the peak value, there is a long platform area; however, after the average crushing force of empty tube reached the peak value, a significant decline occurred, caused by the rapid decrease in load due to the buckling of the pipe wall. With the increase in the relative density of the lattice material, the average crushing force of the pyramidal lattice material-filled tube increased. 


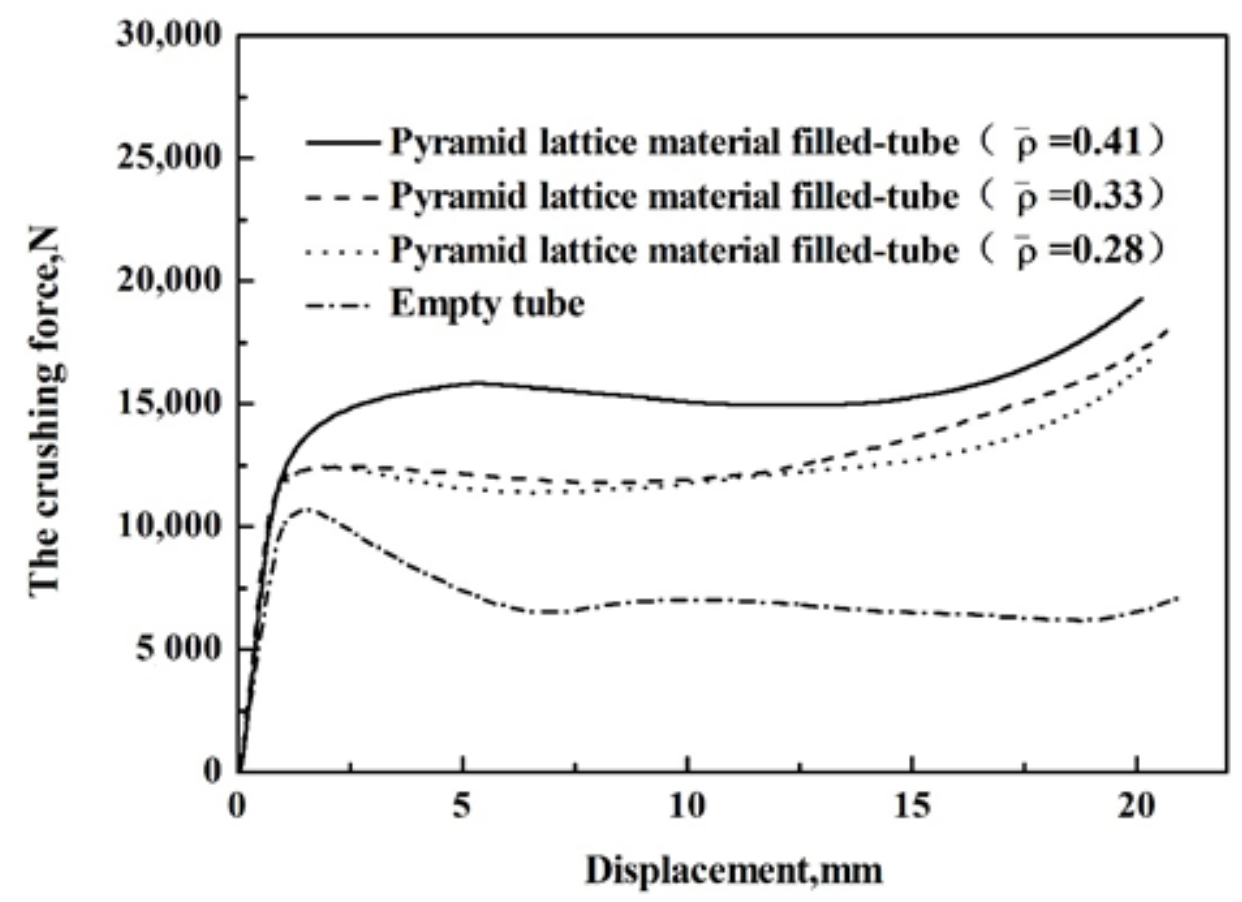

Figure 12. The average crushing force-displacement curves of the pyramid lattice material with different relative densities.

\subsection{Effects of Structural Parameters on Energy Absorption}

Energy absorption per unit volume is important in the design of such cellular materials and can be given by

$$
W=\int_{\varepsilon_{1}}^{\varepsilon_{2}} \sigma d \varepsilon
$$

where $\varepsilon_{1}$ and $\varepsilon_{2}$ are the compressive strains, and $\sigma$ is the compressive stress.

Energy absorption per unit mass is important in the design of such cellular materials and can be given by

$$
W=\frac{\int_{s_{1}}^{s_{2}} F d s}{m}
$$

where $s_{1}$ and $s_{2}$ are the compressive displacement, $\mathrm{m}$ is the mass, and $F$ is the compressive force.

The presented stress-strain behaviour directly affects the energy absorption per unit volume of the pyramidal lattice material, empty tube, and pyramidal lattice material-filled tubes. Up to strains of $5 \%$, for all samples, the energy absorption per unit volume is similar, while when increasing the strain, the difference between samples increased as shown in Figure 13a-c. With increasing strain, the energy absorption per unit volume of pyramidal lattice material-filled tubes increases to above that of the pyramidal lattice material and empty tube and exceeds the sum thereof. For example, at a strain of 0.5 , the sum of the energy absorbed by the pyramidal lattice material-filled empty tube is $11.1 \mathrm{MJ} / \mathrm{m}^{3}$, but the energy absorbed by the corresponding pyramidal lattice material-filled tube is $15.5 \mathrm{MJ} / \mathrm{m}^{3}$ (Figure 13a). The energy absorption per unit mass of the pyramidal lattice material, empty tube, and pyramidal lattice material-filled tubes at a strain of 0.5 is shown in Table 2. From the table, it is clear that the pyramidal lattice material-filled empty tube provided a significantly higher energy absorption per unit mass than the sum of the energy absorption per unit mass in the pyramidal lattice material and empty tube. When the relative density of the lattice material was 0.41 , the energy absorption per unit mass of lattice material-filled was $200 \mathrm{~J} / \mathrm{g}$, and the sum of the energy absorption per unit mass for the pyramidal lattice material and empty tube was $187 \mathrm{~J} / \mathrm{g}$. The pyramidal lattice material inside the tube helps to absorb more energy and bear a higher compressive load than the empty tube. These 
results indicate the potential to tailor the geometric features of multi-material structures to achieve excellent strength and energy-absorption properties.
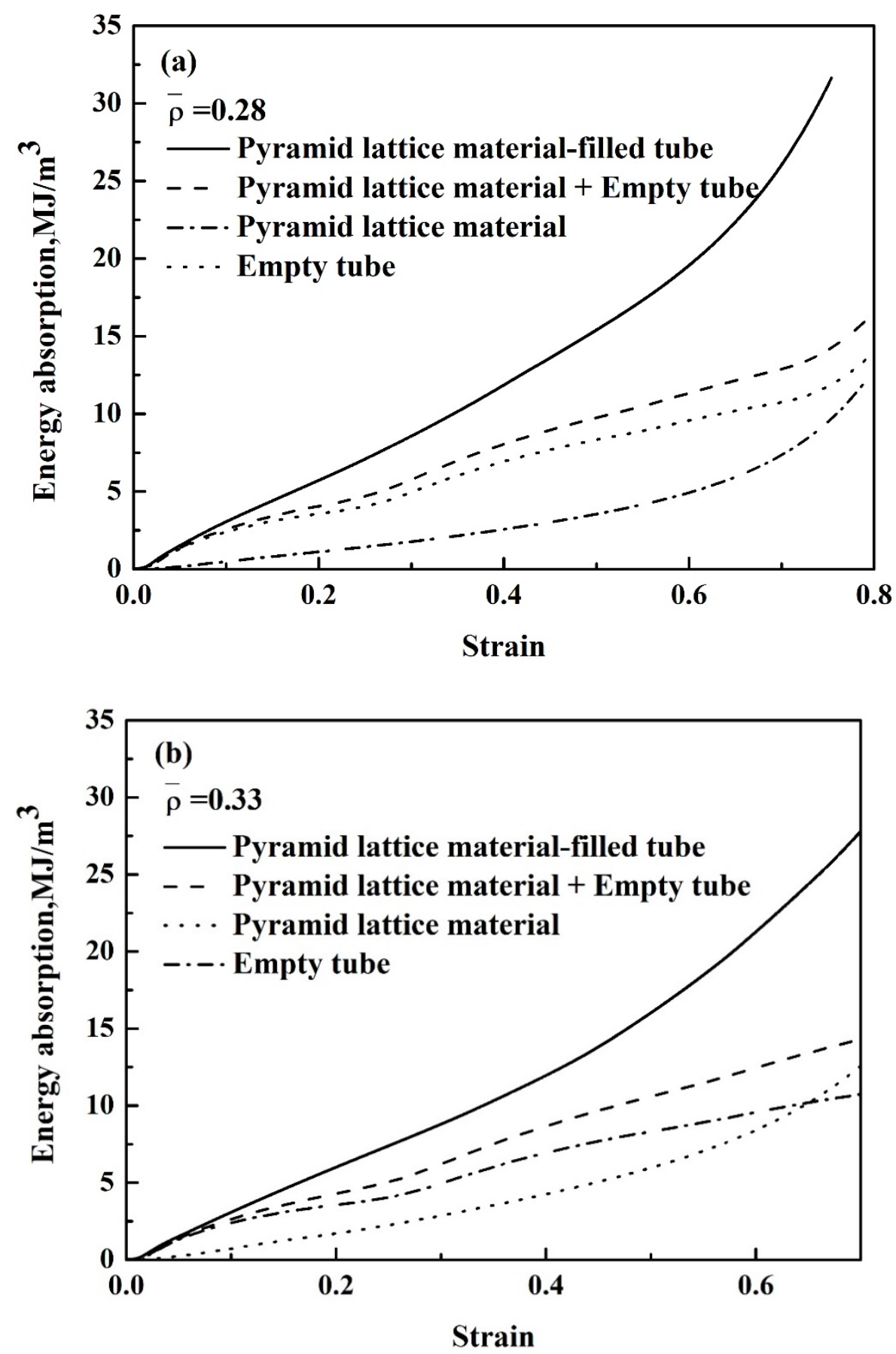

Figure 13. Cont. 


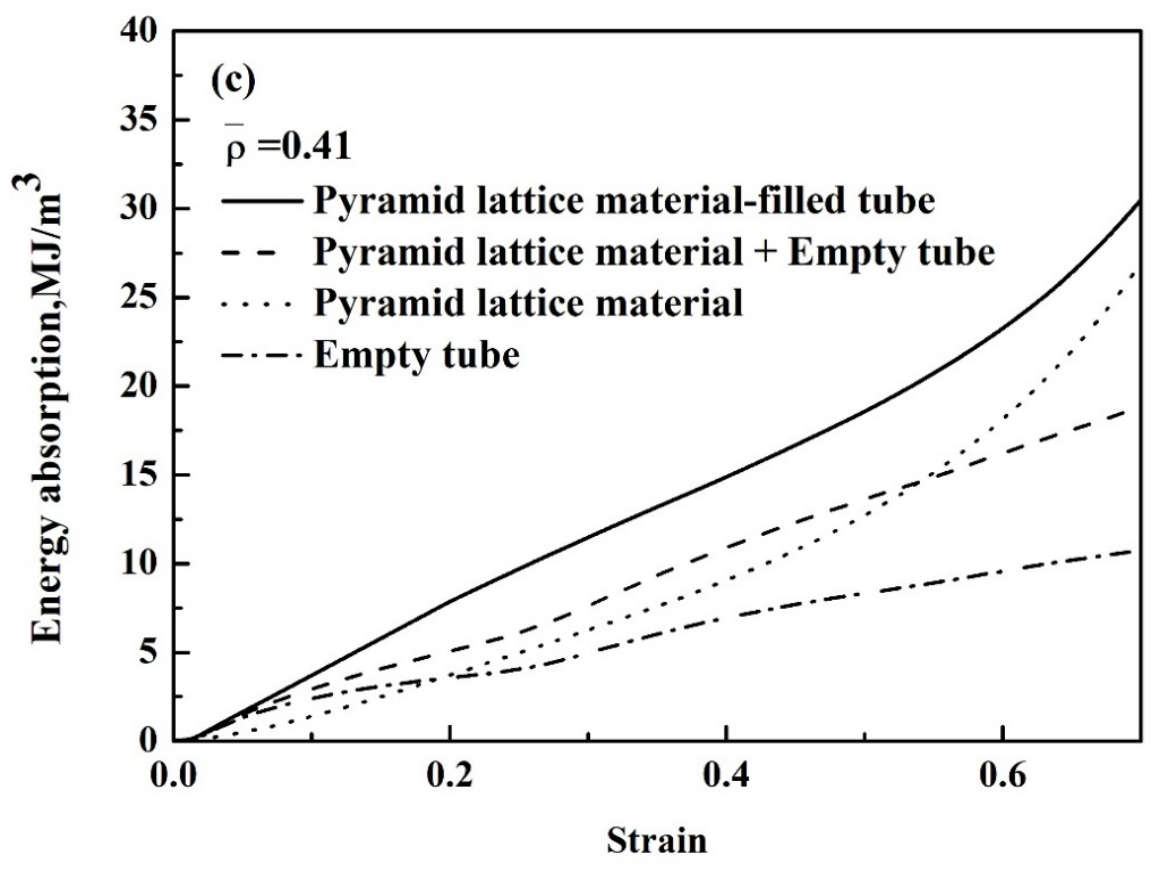

Figure 13. Energy absorption per unit volume of the pyramid lattice material-filled tube with lattice materials of different relative densities (a) 0.28 , (b) 0.33 , (c) 0.41 .

Table 2. Energy absorption per unit mass of the pyramid lattice material-filled tube, lattice material, and empty tube.

\begin{tabular}{cccc}
\hline Sample & $\begin{array}{c}\text { The Relative } \\
\text { Densities of Lattice } \\
\text { Material }\end{array}$ & $\begin{array}{c}\text { Energy } \\
\text { Absorption (J) }\end{array}$ & $\begin{array}{c}\text { Energy } \\
\text { Absorption per } \\
\text { Unit (J/g) }\end{array}$ \\
\hline Lattice material & 0.28 & 29 & 5.8 \\
Lattice material & 0.33 & 52 & 7.4 \\
Lattice material & 0.41 & 107 & 11.2 \\
lattice material-filled tube & 0.28 & 167 & 15.2 \\
lattice material-filled tube & 0.33 & 175 & 14.5 \\
lattice material-filled tube & 0.41 & 200 & 13.3 \\
Empty tube & & 80 & 13.3 \\
\hline
\end{tabular}

\section{Conclusions}

This study focuses on the mechanical properties of aluminium pyramidal lattice material-filled tubes. It is shown that, unlike empty tubes, the aluminium pyramidal lattice material-filled tubes exhibit four-stage compressive mechanical behaviour. The interaction between lattice material and the empty greatly decreases the stress drop and there is no obvious stress fluctuation. When the relative density of the lattice material is 0.28 and the strain is 0.3 , the energy absorption of the aluminium pyramidal lattice material-filled tubes increases by $26 \%$ compared with the sum of the lattice material and the empty tube. When the relative density of the lattice material is 0.41 and the strain is 0.2 , the stress of the aluminium pyramidal lattice material-filled tubes increases by $24 \%$ compared with the sum of the lattice material and the empty tube. The results also showed that both the mechanical behaviour and energy absorption of the pyramidal lattice material-filled tubes improve as a result of the interaction between the pyramidal lattice material and the empty tube. These results provide guidelines for engineering and developing new thin-walled tube structures with enhanced mechanical properties for a wide range of applications and further development of multi-material structures. 
Author Contributions: Conceptualization, Y.H. and Z.S.; methodology, Y.H., W.Z. and Z.S.; software, Y.H. and Y.X.; validation, Y.H., Y.X. and Z.S.; formal analysis, Y.H. and Z.S.; investigation, Y.H.; resource, Z.S.; data curation, Y.H.; writing-original draft preparation, Y.H.; writing-review and editing, Y.H. and Z.S.; visualization, Y.H.; supervision, Y.H.; project administration, Y.H.; funding acquisition, Y.H., W.Z., Y.X. and Z.S. All authors have read and agreed to the published version of the manuscript.

Funding: This work was funded by the National Natural Science Foundation of China (51671187, 51371167 and 51805462), the natural Science Foundation of Shandong Province (ZR2019MEE074), Key R \& D Program of Shandong Province (2019 JZZY010445) and the International Science and Technology Cooperation Project from Anyang Government/Anyang Key R \& D and Promotion Project (NO. 2020083, NO. 2020081).

Institutional Review Board Statement: Not applicable.

Informed Consent Statement: Not applicable.

Data Availability Statement: The data presented in this study are available in insert article.

Conflicts of Interest: The authors declare no conflict of interest.

\section{References}

1. Luo, X.; Xu, Y.J.; Nie, L.X.; Gao, Y.; Zhu, J.S.; Li, W.M. The mechanical behavior of thin-walled tube filled with hollow metal spheres. Compos. Struct. 2015, 133, 124-130. [CrossRef]

2. Hangai, Y.S.; Otazawa, T.U. Aluminum alloy foam-filled aluminum tube fabricated by friction stir back extrusion and its compression properties. Compos. Struct. 2017, 183, 416-422. [CrossRef]

3. Ahmad, B.; Mustafa, S.; Abdul, G.O. On the crashworthiness performance of thin-walled energy absorbers: Recent advances and future development. Thin-Walled Struct. 2017, 118, 137-163.

4. Sun, G.Y.; Li, S.F.; Liu, Q.; Li, G.Y.; Li, Q. Experimental study on crashworthiness of empty/aluminum foam/honeycomb-filled CFRP tubes. Compos. Struct. 2016, 152, 969-993. [CrossRef]

5. Duarte, I.; Vesenjak, M.; Love, K.O. Dynamic and quasi-static bending behavior of thin-walled aluminium tubes filled with aluminium foam. Compos. Struct. 2014, 109, 48-56. [CrossRef]

6. Movahedi, N.; Linul, E. Quasi-static compressive behavior of the ex-situ aluminum-alloy foam-filled tubes under elevated temperature conditions. Mater. Lett. 2017, 206, 182-184. [CrossRef]

7. Ranwaha, N.; Chung, K.Y.S. The effects of blast-induced fragments on cellular materials. Int. J. Impact Eng. 2016, 92, 50-65. [CrossRef]

8. Xia, X.; Zhang, Z.; Zhao, W. Acoustic properties of closed-cell aluminum foams with different macrostructures. J. Mater. Sci. Technol. 2017, 33, 1227-1234. [CrossRef]

9. Duarte, I.; Krstulovi, L.; Vesenjak, M. Characterisation of aluminium alloy tubes filled with aluminium alloy integral-skin foam under axial compressive loads. Compos. Struct. 2015, 121, 154-162. [CrossRef]

10. Hanssen, A.N.; Langseth, M.; Hopperstad, O.S. Static and dynamic crushing of circular aluminum extrusions with aluminum foam filler. Int. J. Impact Eng. 2000, 24, 475-507. [CrossRef]

11. Duarte, I.; Vesenjak, M.; Krstulovic, O. Compressive performance evaluation of APM foam filled tubes. Compos. Struct. 2015, 134, 409-420. [CrossRef]

12. Taherishargh, M.; Vesenjak, M.; Belova, I.V. In situ manufacturing and mechanical properties of syntactic foam filled tubes. Mater. Des. 2016, 99, 356-368. [CrossRef]

13. Linul, E.; Movahedi, N.; Marsavina, L. The temperature effect on the axial quasi-static compressive behavior of ex-situ aluminum foam-filled tubes. Compos. Struct. 2017, 180, 709-722. [CrossRef]

14. Niknejad, A.; Rahmani, D.M. Experimental and thepretical study of the lateral compression process on the empty and foam-filled hexagonal columns. Mater. Des. 2014, 53, 250-261. [CrossRef]

15. Cao, J.; Khajepour, A.; Gan, N.F.; Long, Y.C.; Huang, J. Crashworthiness of functionally graded density aluminum foam-filled tapered thin-walled structures. J. Automot. Saf. Energy 2016, 7, 35-48.

16. Gumruk, R.; Mine, R.A.W. Compressive behavior of stainless micro-lattice structures. Int. J. Mech. Sci. 2013, 68, 125-139. [CrossRef]

17. Tancogne, D.T.; Spierings, A.B.; Mohr, D. Additively-manufatured metallic micro-lattice materials for high specific energy absorption under static and dynamic loading. Acta Mater. 2016, 99, 581-591.

18. Ye, G.Y.; Bi, H.J.; Hu, Y.C. Compression behaviors of 3D printed pyramidal lattice truss composite structures. Compos. Struct. 2020, 233, 111706. [CrossRef]

19. Huang, Y.J.; Xue, Y.Y.; Wang, X.F. Mechanical behavior of three-dimensional pyramidal aluminum lattice materials. Mater. Sci. Eng. A 2017, 696, 520-528. [CrossRef] 
20. Xue, Y.Y.; Wang, X.F.; Wang, W.; Zhong, X.K.; Han, F.S. Compressive property of Al-based auxetic lattice structures fabricated by 3-D printing combined with investment casting. Mater. Sci. Eng. A 2018, 722, 255-262. [CrossRef]

21. McKown, S.; Shen, Y.; Brookes, W.K.; Sutcliffe, C.J.; Cantwell, W.J.; Langdon, G.S.; Nurick, G.J.; Theobald, M.D. The quasi-static and blast loading response of lattice structures. Int. J. Impact Eng. 2008, 35, 795-810. [CrossRef]

22. Gümrük, R.; Mines, R.A.W.; Karadeniz, S. Static mechanical behaviours of stainless steel micro-lattice structures under different loading conditions. Mater. Sci. Eng. A 2013, 586, 392-406. [CrossRef] 